\title{
Carbon C 13 Sodium Octanoate
}

National Cancer Institute

\section{Source}

National Cancer Institute. Carbon C 13 Sodium Octanoate. NCI Thesaurus. Code C98279.

The sodium salt form of the medium-chain fatty acid octanoate, and labeled with the isotope carbon C13, used in the octanoate breath test (OBT) to assess hepatic mitochondrial function. Upon ingestion of carbon C13 octanoate, this agent is metabolized in the liver via mitochondrial beta-oxidation. Upon determination of the ratio between $13 \mathrm{C} / 12 \mathrm{C}$ of CO2 in exhaled breath, liver function can be assessed. 